\title{
Mission Impossible: \\ The Governance of European Science and Technology
}

\author{
Peter S. Biegelbauer
}

The idea of European integration has found its first truly dynamic and peaceful expression in the European Union. With the Single European Act of 1987, in hindsight the end of the Eurosklerosis, and the historic fall of the iron curtain in 1989 the European integration process has obtained a new dimension. Nevertheless, the eastern enlargement is a challenge for the Union, carrying both chances and risks. In this situation, the analysis of science and technological development - after agriculture and structural funds the thirdmost important European Union policy field in terms of budgetary allocations - seems to be justified.

Despite a number of successes, for instance the fostering of a number of areas generally regarded as critical for the future of the region and the induction of the establishment of a sizable number of transnational research networks, the European Union's science and technology programmes have been criticised for quite a few reasons, too. Such criticism has addressed the lengthy bureaucratic cycles, the undemocratic decision-making processes and the dismal impact of the mostly near-application research results on society, to name a few examples.

To understand the science and technology fields' current state of affairs on the European Union level, four questions shall be asked:

- How did the European Union's science and technology programmes evolve?

- What are the most problematic areas of these programmes, with respect to their structure and their governance?

- Which explanations are available for the existence of these problems?

- Are there any policy solutions for the problems at hand or even reforms under way? 


\section{A Short History of European Science and Technology Programmes}

Despite the long history of Europe, continental co-operation can look back only on a fairly short history. Forced to cooperation by the devastating effects of World War II and the subsequent bipolar world system, the European Coal and Steel Community was founded in 1951, six years later to be superseded by the European Economic Community (EEC), later named the European Communities (EC), today's European Union (EU). The organisation had two major goals: to establish a peaceful order in Western Europe, which would be able to prevent wars in the future, and to enable the capitalist pluralist part of the continent to flourish economically. Both goals were understood as interlinked.

In the first two decades science and technology (S\&T) played a rather marginal role in the EEC's policies. Besides research in the atomic energy programme of the EEC, performed under the EURATOM treaty, only a small number of projects was carried out, primarily in industry near research and development (R\&D). Discussions regarding the necessity of common efforts in S\&T intensified in the 1960s, when the industrial competitiveness of Europe diminished - a fact analysed in several books during this time (see ServanSchreiber, 1968; European Commission, 1970). Nevertheless, it was only at the beginning of the 1980s, after the effects of the first two oil shocks had ebbed, that a major European S\&T programme was realised.

This initiative, the First Framework Programme, was a reaction to the loss of core competencies and market shares of
West European companies in comparison to Japanese and US-American firms. It was also a response to the US Strategic Defence Initiative, SDI, which was supposed to provide a strong impetus not only to military, but also civilian R\&D. Running from 1984 to 1987, the First Framework Programme disposed over funds of 3,8 billion ECU ${ }^{1}$. Together the atomic energy programmes and the today still existing industrial R\&D initiative ESPRIT (European Strategic Programme for $R \& D$ in Information Technology) received the lion's share of the First Framework Programme. Industrial $R \& D$ made up almost $30 \%$ of the programme.

The Second Framework Programme was with a total sum of 5,4 billion ECU not only larger than its predecessor, but was established as a preferential policy field of the EC through a treaty, the Single European Act of 1986 (see also Süß, 1993: 295). Already $60 \%$ of the initiative were targeted at industrial $R \& D$, with information and communication technologies receiving $41 \%$ of the total. The Second Framework Programme was active from 1987-1991.

The Third Framework Programme, running from 1990-1994, with 7,3 billion ECU again was a substantial enlargement in comparison to its predecessor. It featured an elaborate structure with three concentrations, basic technologies, natural resources and human resources, and fifteen specific programmes. It is interesting to notice the rising importance of mobility programmes for researchers, which almost doubled to $9,1 \%$ of the total on the first three Framework Programmes, (see European Commission, 1992; Berka et al., 1994). 
During this time-span the Maastricht treaty of 1992 transformed the EC into the EU and regulated anew the EU's S\&T programmes in the articles 130f-p. Of special interest are the first paragraphs: while article $f$ postulates the raising of the EU's competitiveness, also through concerted actions of the S\&T programmes with other policy areas, article g broadly explains the measures to be taken and article $\mathrm{h}$ states that the R\&D activities of the EU and its member states shall be co-ordinated, with the Commission having the explicit right to take - in co-ordination with the member states - the necessary measures to do so (EC Council and Commission, 1992: 55-58). Especially the articles f and $h$ of the Maastricht treaty can be seen as another indication for the determination of the EU to strengthen its S\&T programmes.

The Fourth and currently running Framework Programme is active from 1994-1998. It is funded with 13,2 billion ECU, including the still operative EURATOM activities, and consists of four action lines, the $R \& D$ programmes, the co-operation with third countries, the diffusion of $R \& D$ results and the education and mobility of researchers, and more than 2.000 topics. Furthermore, activity one, with $86 \%$ the by far largest of the four action lines, displays a list of subprograms for information technologies and communication, industrial and material technologies, energy, life sciences, environment, transport and targeted socio-economic research. In the course of this latter programme, for the first time the social sciences have been provided with an own subprogram, which, however, received a mere $1 \%$ of the total. Nevertheless, this single percentage point translates into approximately 160 projects with a total of more than 1.000 research teams. ${ }^{2}$ (Table 1 provides an overview of the Fourth Framework Programme.) $)^{3}$

This impressive initiative already encompasses around $4 \%$ of the EU fifteen ${ }^{4}$ member states' total R\&D expenditure. This might seem a small number, but it is not. After all, most EU funding happens on a "shared-cost" basis, which includes the allocation of a maximum of $50 \%$ of total project costs by the EU. This means that at least $50 \%$ of the costs have to be covered by other sources, many of which are originating at the level of the individual member states.

In addition, it is important to notice that the lion's share of this money is pure research money, i.e. no infrastructure costs are covered. Moreover, since the Framework Programme can finance not more than $20 \%$ of the projects seeking funding, a large number of project groups regularly are filing applications with other sources (cf. Kaukonen, 1998). Practically all of these projects are fulfilling the main criteria of the EU guidelines: they deal with topics of relevance to Europe and involve at least two organisations (typically research projects involve between five to ten partners) located in two different countries, which are either EU member states or third countries associated with the Fourth Framework Programme. As many of these projects are of high quality, quite a few are funded by alternative sources and thereby create an additional impact on European S\&T, without direct EU-involvement. 
Table 1.EC and Euratom Framework Programmes

Field

Funding

(million ECU)

I. Information and communications technologies

3,668

1. Telematics applications

913

2. Advanced communication technologies and services

3. Information technologies

II. Industrial technologies

2,140

4. Industrial and materials technologies

1,833

5. Standards, measurements and testing

III. Environment

6. Environment and climate

7. Marine sciences and technologies

IV. Life sciences and technologies

1,709

8. Biotechnology

9. Biomedicine and health

10. Agriculture and Fisheries

V. Energy

11. Non-nuclear energy

12. Nuclear fission safety (Euratom)

1,076

441

13. Controlled thermonuclear fusion (Euratom)

VI. Transport

14. Transport

263

15. Targeted socio-economic research

Co-operation with third countries and international organisations

ACTIVITY 3

Dissemination and exploitation of results

ACTIVITY 4

Stimulation of the training and mobility of researchers Total

792

Source: European Commission, http://www.cordis.lu/info/frames/if006_en.htm; 01-16-1998

\section{The Fifth Framework Programme}

Since 1995 the Fifth Framework Programme is being debated by the organs of the EU, the member states and numerous interest groups. According to the recent EU Research Ministers' Council agreement from the December 22, 1998, displayed in tables 2 and 3, the programme will feature a structure quite different from its predecessors, since it is ordered after goals rather than following the disciplinary borderlines of S\&T fields. 
Table 2. EU Council Agreement on the Four Thematic Programmes and Budgetary Resources under the First Activity of the Fifth Framework Programme( in million EURO)

Theme 1: Quality of Life, Management of Living Resources

- Key actions

. Food, Nutrition and Health

290

. Control of Infectious Diseases

300

. The "Cell Factory"

400

. Environment and Health

160

. Sustainable Agriculture, Fisheries and Forestry

520

. The Ageing Population and Disabilities

190

- RTD activities of a generic nature

483

- Support for research infrastructure

Theme 2: User-Friendly Information Society

3,600

- Key actions

. Systems and Services for the Citizen

646

. New Methods of Work and Electronic Commerce

547

. Multimedia Content and Tools

564

. Essential Technologies and Infrastructures

1,363

- RTD activities of a generic nature

319

- Support for research infrastructure

Theme 3: Competitive and Sustainable Growth

- Key actions

. Innovative Products, Processes and Organisation

. Sustainable Mobility and Intermodality

. Land Transport and Marine Technologies

320

. New Perspectives for Aeronautics

700

- RTD activities of a generic nature

546

- Support for research infrastructure

Theme 4: Energy, Environment and Sustainable Development

4.1 Environment and Sustainable Development

- Key actions

. Sustainable Management and Quality of water

1,083

. Global Change, Climate and Biodiversity

254

. Sustainable Marine Ecosystems

301

170

. The City of Tomorrow and Cultural Heritage $\quad 170$

- RTD activities of a generic nature

119

- Support for research infrastructure

4.2 Energy

- Key actions :

. Cleaner Energy Systems, incl. Renewables

. Economic and Efficient Energy

- RTD activities of a generic nature

Source: European Commission, http://www.cordis.lu/fifth/; 02- 01-1999;

Council press release $14135 / 98$ provisional 
Although the Fifth Framework Programme has been growing at a slower rate than its predecessors, it is about 4,6\% larger than the Fourth Framework Programme. Of the 14.960 million EURO, which have been reserved for the Fifth Framework Programme, 13.700 million will be spent under the European Community Treaty - this sum is displayed in tables 2 and 3 - and 1.260 million under the EURATOM Treaty. The Fifth Framework Programme is going to be active from 1999-2002.

\section{The Governmental Process of EU S\&T Programmes}

The Framework Programmes have received widespread appraisal for their ability to create awareness of key problems in S\&T as well as for their strength in the creation and linkage of research groups throughout Europe, with many positive subsequent effects resulting from the diffusion of knowledge and research skills. However, despite their growth in size and complexity, the
Framework Programmes persistently have been criticised on a number of reasons. The scientific quality of the initiative, the lack of transparency in decisionmaking regarding the evaluation of the proposals as well as the selection of the reviewers, the strong orientation of the initiative on industrial technologies, the length of procedures and the fact that knowledge about policy relevant studies is not widely dispersed by and in the European Commission have been attacked, to list a few regularly named aspects (cf. Trute, 1994: 5).

On a more general level, an important charge against the Framework Programmes has addressed its inflexibility resulting in extensive lead times with regards to the reaction to real-life problems. Moreover, the Commission's efforts of enlarging the Framework Programmes not only on a financial, but also a on thematic basis, have been met with resistance by a number of countries, as for example Germany, which fear the Commission might draw competencies previously located at the na-

Table 3. EU Council Agreement on the Programmes and Budgetary Resources under the Second, Third and Fourth Activity of the Fifth Framework Programme, (in million EURO)

Second Activity:

Confirming the International Role of Community Research

Third Activity:

Promotion of Innovation, Encouragement of SMEs

Fourth Activity:

Improving Human Research Potential

Source: European Commission, http://www.cordis.lu/fifth/; 02- 01-1999;

Council press release 14135/98 provisional 
tional level. A further major concern about the initiative was the fact that science and technological development were to be used by the EU to foster regional development and the integration of the Union. The critique especially from the Northern European countries was that excellency has to reign supreme in science, so as to assure optimal outcomes. It was also in this respect that the European Commission has been frequently charged with power peddling in the evaluation process, thereby making sure the outcome of the process would be in conformity with the political goals of the Framework Programmes. ${ }^{5}$

To arrive at an understanding of the EU S\&T programmes' problem areas, it is necessary to take first a closer look at the EU-level governance structures, followed by an analysis of the interest aggregation processes between the EU organs and its member states.

As reflected in Figure 1, at the level of the EU three institutions are of central importance. These three institutions are the European Parliament, with altogether 4.000 staff members, including the Committee on Energy, Research and Technology (CERT), the European Commission, itself consisting of the $24 \mathrm{Gen}$ eral Directorates and 21.000 staff members (including 3.700 personnel in R\&D), and the Council of the European Union, with its general directorate of 2.500 staff members, together making up the core of the decision making institutions of the EU. The Council of the EU consists of the European Council, the summit of the member states' political leaders, and the Councils of Ministers, each made up of the heads of the respective national branch ministries. Being part of this council system, the council of the mem- ber states' research ministers is of key importance for strategic long-term decisions in the S\&T policy field. The medium-term management of the S\&T programmes is carried out by programme committees, part of the famous comitology, ${ }^{6}$ which consist of delegates of the member states and are headed by commission personnel.

Another part of the policy-finding structure are advisory councils. The most important of these bodies is CREST (Comité de la Recherche Scientifique et Technique), consisting of leading administrators of the most important national S\&T governance institutions. CREST, founded already in 1974 , is a forum for strategic decision-making processes and is advising both the European Council and Commission. ${ }^{7}$

The other advisory councils are the 1984 established IRDAC (Industrial Research and Development Advisory Committee), representing the European industry and the ESTA (European Science and Technology Assembly), created in 1994 and consisting of representatives of the academic and industrial research communities. ${ }^{8}$ Of these two, IRDAC has been named by interview partners as having the stronger, if still limited, clout.

Of course, the process of interest aggregation regarding S\&T policy on the EU level is more intricate than suggested by the institutional structure displayed in Figure 1, already because it includes more institutional actors than are arrayed there. At this point a short look at theories, which have been used for the analysis of the major EU actors' interactions will be of help. For the understanding of the EU's governmental process three strands of theories ${ }^{9}$, which are almost paradigmatic, have reached major 
Figure 1. The Organs of the European Union as Relevant For S\&T Governance

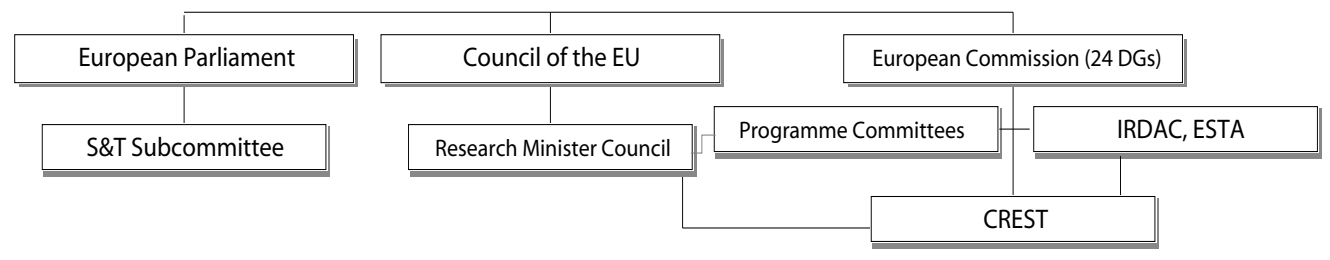

importance.

The first group of theories is rather optimistic of the European integration process and might be called supranationalist, including federalism, a school of theories based upon structuralist thinking, which was specifically influential in the two decades after WWII (e.g. Burgess, 1989; Wistrich, 1988). The supranational group also includes neofunctionalism, a school of theories based upon pre-WWII functionalist thinking, which rose to new heights in the 1960s (for example Haas, 1968). By way of characterisation of the two schools one might interpret their central message as the possibility of European integration up to the point of a United States of Europe, whereby federalism was more optimistic about the possibilities of such an integration as was neofunctionalism. With regards to the utilised methods federalism was focusing more on the structures, whereas (neo-)functionalism was centring on the processes of such an integration effort.

As a reaction to the stalling of the European integration process beginning with the mid 1960s, a second group of theories gained ground during the 1970s and 1980s, which might be called statecentrist. Here one can find on the one hand the intergovernmental theories, which were based on the realist school of international theory, understanding the actions of the states primarily in a utilitarian framework of thinking and before a rather anarchic background of international relations (e.g. Hoffmann, 1964; 1968). On the other hand one can find interdependency theories based upon the acceptance of the interdependent nature of relationships between the states, setting out to explain phenomena as the globalisation process (e.g. Webb, 1983). Both groups of theories offer a rather pessimistic view on the European integration process, with intergovernmental theories being outright gloomy and interdependency theories being rather skeptical of integration, with the latter, however, accepting the possibility of an integration driven by pressures from outside.

As a result of the revived European integration process, the 1980s necessitated a new strand of theories, which are combining some of the virtues of the two older schools of theories. Co-operative federalism and multi-level system theo- 
ries have been developed in the 1980s and 1990s, in acceptance of the possibility of a "stop-and-go" integration process, which is based on a much more complex negotiation process than was assumed by most previous analyses..$^{10} \mathrm{As}$ multi-level system theories are a quite flexible tool for the description and analysis of EU decision-making processes, their central idea shall be shortly characterised next.

The interest formation in the EU takes place on a number of levels, three of which are of major importance for this analysis. In a schematic and simplifying manner one could say that at the supranational level the EU organs, which have been discussed already, at the national level the national governments and at the regional level a multitude of interest groups can be found. In modelling the interest aggregation mechanisms the internal bargaining processes between the actors on the national level shall be excluded as much as the interactions amongst the interest groups at the regional (and national) level.
What is important to notice even in such a simplified model, as displayed in Figure 2, is the astounding complexity of interactions between the three levels. Interest aggregation processes take place between the interest groups at the regional level, consisting primarily of academic and non-academic research organisations, and the institutions at the national level, mostly ministries and other governmental agencies. Similar processes can be found between the regional level and the EU level, where regional and national interest groups increasingly form Europe-wide associations, as different from each other as EUROHORCS (EU Research Organisations, Head of Research Councils) and EITIRT (European Information Technology Round Table of Industry), to lobby the EU organs. Interest aggregation takes place also between the national level and EU organs through the European Council, the permanent representation of the member states and other institutional access points.

These processes are complicated by the fact that the interactions of all in-

Figure 2. EU S\&T Policy Interest Aggregation

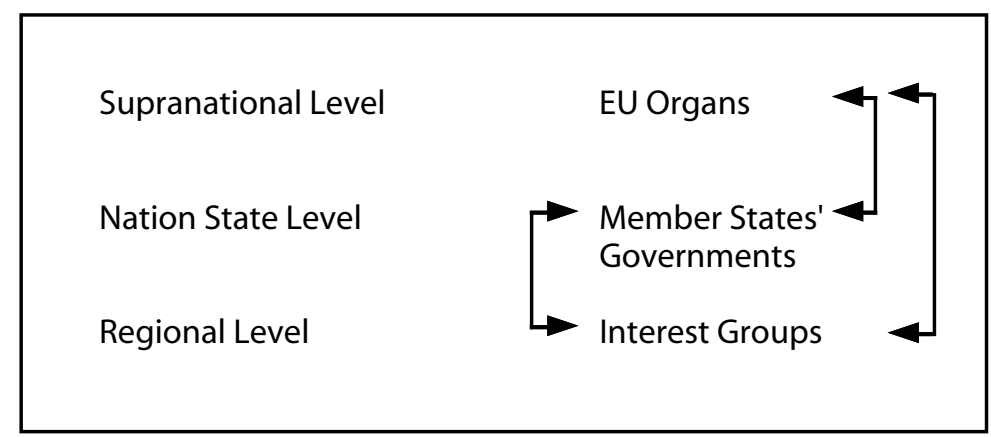


volved actors with their respective environment are Janus-shaped. All serve as interest aggregating mechanisms in the sense that interest groups are representing their members, ministries their clients, and EU institutions the countries or organisations they are consisting of or linked with. Yet all institutions are independent agents themselves, i.e. interest groups, ministries and EU general directorates all have their bureaucratic selfinterest to grow and expand their staff numbers and extend their radius of influence.

The merits of this approach to the European integration is the relatively close understanding of the involved institutions' interactions and interest aggregation processes. However, interest representation at the EU-level takes place along functional as well as national lines. Whilst the multi-level system literature displays a clear understanding of the functional level, it tends to disregard the national level as such, as well as the latest steps in the integration process, which are incorporated in the Maastricht and Amsterdam treaties, bringing the EU nearer to the principles of supranationality.

The national level is not the focal point of interest for the proponents of the multi-level approach. Nevertheless, the strength of the national interest aggregation mechanisms is ingrained in the institutional structure of the EU institutions and goes back to the founding days of the EEC, when the nation states were, with the exception of the international regime of the UNO, the only major actors on the international level. In recent years the Commission has tried to foster the creation and representation of interests outside the structures of the nation states, in the form of associations of functional representation on the European level. However, Anke Peschke (1998) finds in an analysis of this process that transnational interest aggregation works rather badly in the case of EU S\&T politics.

By summarising one can say that, both, network and multi-level as well as international theory based, approaches have their merits and blind spots. Ideally they have complementary functions and shall be used this way here (for a comparison of both approaches see Süß, 1993: 315).

\section{Diversity as a Problem of Governance}

The perhaps most important underlying reason for the problems of the Framework Programmes is that the enormous diversity of interests resulting from the variety of history, culture and socio-economic structures in the 15 member states is the key constraint of governance in the EU. To paraphrase the Commission's “Greenbook on Innovation", in the case of S\&T the structures of industry and its specialisation's are differing widely in Europe, as is the technological niveau of the member states. The $R \& D$ expenditures of the states are varying to the factor of 11 with private industry funding $R \& D$ between $30-70 \%$. The economies of some countries feature leading multi-national companies, other national economies are based almost exclusively on small and medium sized enterprises (European Commission, 1995: 19). This wide variety in the nature of the fifteen national S\&T systems is a major reason for the complexity of the 
EU's governmental process, which as a result of this diversity is faced with a number of cleavages in the interest structure of the major actors in the EU ${ }^{11}$. On an analytic note these cleavages can be disaggregated into four different exemplars $^{12}$. One such cleavage is inherent to the structure of the EU organs, the other three are a result of the diversity amongst the member states.

The perhaps most serious conflict on the side of the member states has arisen between the economically highly and less highly developed countries. The economically highly developed countries are mostly interested in utilising EU S\&T initiatives as possibilities to gain a leading edge in the high-technology sectors, which by and large are decisive for the global economic competition. In contrast, the economically less developed countries often are missing basic S\&T institutions and would like to use the Framework Programmes for basic S\&T investments. Specifically in the aftermath of the EU's Southern Enlargement (the admission of Greece, Portugal and Spain), countries with a highly differentiated S\&T system as such France and Germany were confronted with S\&T systems consisting of a quite limited number of public universities and competitive small and medium sized private enterprises.

With respect to the discussion over the Fifth Framework Programme, this has led to the proposal of a number of highly developed countries, among them Finland and Germany, allowing for variations in geographic participation. Under such a construction different priority themes would be possible depending on the regions being addressed (European Commission, 1997b).
Another important cleavage between EU member states can be found between the large and the small countries. By virtue of the pure size of its S\&T system, a large country needs always less co-operation, even in the case of economically less highly developed countries, than a small country. The necessity of co-operation programmes arises for a small country in all aspects of S\&T. It might not be possible to have all S\&T fields represented in the higher education system of a small country, but for sure it is not possible to harbour more than only a few of the most important industrial sectors, which are necessary for the creation of successful knowledge based economies.

This small country problem ${ }^{13}$ is also reflected in the S\&T policies of the member states. Generally speaking, the large European countries tend to display a smaller number of priority areas, which often are complementary to the already existing specialisation's of the respective national economy, but a larger number of policies with many instruments to stimulate development in these areas. The smaller European countries are more likely to have a larger number of areas they would like to cover, but a limited set of policy instruments at their discretion.

Analysing the country positions on the Fifth Framework Programme it is also interesting to notice that on the one hand a coalition between Austria, Portugal and Sweden has pushed for the inclusion of social science in the Framework Programme besides industrial research. On the other hand large countries such as Germany and the UK focus their opinions very much on industrial research, the major goal of the EU's S\&T 
programmes, with France actively opposing the inclusion of social science into the Fifth Framework Programme according to a number of interview partners, a view reflected in the position of Edith Cresson, Commissioner for Research, Innovation, Education, Training and Youth.

Finally, the last major cleavage exists between these countries which are inclined to use S\&T programmes aggressively for the creation of competitiveness and those who are less keen on applying such tools. Traditionally France has been the country advancing the common European S\&T programmes, specifically for the utilisation of such initiatives for competitiveness issues. It was a French book which initiated a Europewide discussion on S\&T policies (Servan-Schreiber, 1968) and it was a French initiative which resulted in a memorandum of the European Commission on a common industrial policy, foreseeing a common S\&T policy and including modern instruments as foresight studies. Traditionally it has been Germany, which has been rather cautious about S\&T initiatives on the EU level, often fearing the creation of instruments, which might interfere with market forces. ${ }^{14}$

In the discussion addressing the Fifth Framework Programme these ideological differences are reflected in the weight given to the subsidiarity principle by Austria and Germany, with France favouring closer co-operation and co-ordination between the member states and the EU. Indeed, the German position takes a strong stance with respect to the utilisation of the existing national S\&T systems as the very basis for the Framework Programmes under the prin- ciple of subsidiarity, while the French position repeatedly makes mention of the need to co-ordinate national and community policies. These differences are as much a reflection of the political culture of the countries in discussion as well as the actual set-up of the polities in these countries, favouring federalisation or centralisation.

As has been said, three cleavages arise on the side of the EU member states, but one cleavage is inherent to the structure of the EU organs. With respect to the latter, it is important to understand the adversarial nature of the EU organs. Typically, the European Commission, the central bureaucracy of the EU, is developing initiatives aiming at the creation of a unified Europe, whereas the European Council, representing the national governments of the member states, is preferring rather cautious steps into the same direction, which, after all, means a loss of competencies for the respective nation-states. The European Parliament regularly favours measures allowing an even faster unification process than the Commission, but, despite the co-decision mechanisms, in many instances it has only control functions.

The development of the Fifth Framework Programme is a case in point. Both Parliament and Commission have opted for an enlarged Framework Programme with a number of changes with respect to the contents of the initiative, including the eradication of the social science research activities, the "targeted socioeconomic research".

While the Parliament in its first reading of the Framework proposal suggested to reserve 16,7 billion ECU for the S\&T initiative, the Commission asked for 16,3 billion ECU, whereas the Council 
finally proposed 14 billion ECU. In addition, the Council's agreement from February 12 of 1998 includes a number of comparatively small content changes to the Commission's proposal, which are more orientated at the structure of the Fourth Framework Programme and again include a nuclear fission programme as well as social science research activities.

Although the political head of DG XII, Edith Cresson, in early summer 1998 went on to insist on the Commission's proposal (see Cresson, 1998: 22; European Commission 1998d), in the Council she was opposed at this point by Austria, the Netherlands, Sweden and the UK, which maintained their position on a freeze of the Framework Programme budget. ${ }^{15}$ Meanwhile, the Commission joined forces with the Parliament, which had reduced its own proposal to 16,3 billion ECU in the second reading in June 1998. In fall of 1998 conciliation talks between Council and Parliament began, which finally led to an - belated - agreement on November 17. The common agreement was formally approved by the European Parliament on December 15 and by the Council of Research Ministers by December 22 of 1998.

With regards to the budget of the Fifth Framework Programme, one can find that with 14,96 billion ECU/EURO it was somewhat closer to the position of the Council than to the positions of Commission or Parliament. With regards to the content of the Programme, it might be seen as coming quite close to the original proposal of the Commission. Nevertheless, a large number of small scale changes were implemented, on the initiatives of the EU Council and Parliament.

\section{The Problem Solutions - Part of the Problem?}

As a result of the delineated problem areas, the decisions of the EU, in the S\&T policy field as well as in others, are often of a rather difficult nature. Long procedures of interest accommodation have to be followed in complex routines to reach compromises between the 15 member states, a number of regional and EU-wide organised interests and the organs of the EU themselves. To cope with this level of complexity, the EU has developed a set of general principles for the construction and performance of all its S\&T initiatives. These six principles are part of two milestones of the European unification process, namely the Single European Act of 1986 and the Maastricht Treaty of 1992. More specifically these are

- the excellency principle: only projects valuable from a scientific standpoint are to be funded; thereby no legal possibility exists for a member state to ask for a certain return of the capital invested into EU funds;

- the cohesion principle: the Framework Programmes are to foster the cohesion of the EU; these member states with lower S\&T capabilities should be drawn into co-operation with those featuring stronger capabilities;

- the co-operation principle: projects have to include at least two partners from different countries, which are either EU member states or which are associated to the Framework Programmes; at least one participating country has to be a member state;

- the subsidiarity principle: all tasks, which might be better fulfilled on the 
national level are not to be taken on by the EU; only when a sufficient "added-value" for the EU can be expected, a certain task falls into the Union's competency;

- the horizontality principle: not selected industries should be financed, but key technologies, which are useful for a number of sectors; thereby the construction of competition-free zones in the economies of the member states should be hindered;

- the precompetitiveness principle: EU S\&T funding has to be pre-competitive in nature; the closer a project is to the market, the smaller the percentage of EU funding may be.

As it turned out over the last years, these principles are not sufficient for a clear distinction between national and EU competencies. Worse, the principles are mere reflections of the EU S\&T policies' dilemmas: on one side the cohesion and co-operation principles can be found, representing the political goals of the unification process. On the other side, there are the excellency, horizontality and precompetitiveness principles, which are aiming at the optimisation of the S\&T funding process. To complicate things, on another level of confrontation between member states and EU Council on the one and European Commission and Parliament on the other side, the subsidiarity principle is to keep the European Commission from taking over these competencies, which are now located at the national level.

When comparing the situation at the supranational level of the EU with interest representation and policy-finding processes of pluralist political systems at the national level, it becomes obvious that, besides a higher complexity of the situation caused by a larger number of actors and a lesser number of guidelines, the differences between the actual procedures are not too large. ${ }^{16}$ Similar to the differences between the formal and informal guidelines for policy-finding routines in pluralist political systems, exemplified in the differences between constitutions and daily politics ${ }^{17}$, the gap between the above six principles reflecting the spirit of the EU's constitution, its multilateral treaty system, and the actual procedures loom large.

An example might suffice here: Whereas it is a commonly accepted axiom of EU policy-making that no member state can ask for a juste retour, a return of the capital paid into EU funds, the S\&T programmes are analysed after this viewpoint. As a result in each national administration people are busily producing charts showing the return of what "our country has paid to the Union". This is even the case for those Central and Eastern European accession candidates, which are not yet members of the EU, but can participate in the Fourth Framework Programme.

On a more normative level, it appears that despite the deficiencies of the six above listed principles, at the moment there is no politically viable alternative for their existence - similar to the situation the Framework Programmes themselves are in. Nevertheless, the discussion of the principles' relative weight is ongoing (see Sharp, 1998). By way of thinking about policy suggestions a possibility might be a distinction between rather basic or strategic science oriented research and rather application and technology oriented research and technological development. Whereas research of the first category seems sensi- 
ble only under the full acceptance of the excellency principle, the rather technology oriented side of research may be possible under a weaker form of the excellency principle's application, too. After all, basic science is research on the frontiers of knowledge, which is almost by definition promising only when the most original research proposals are carried out. This would appear to be less the case for application oriented research and technological development. Consequently, the role of the cohesion principle might be lessened for more basic science oriented research - in exchange for the strengthening of the excellency principle - but may be kept strong for the rather application and technology oriented research and technological development. ${ }^{18}$

Another discussion has centred on the question if the EU S\&T initiatives should concentrate so much on technology rather than on science and on hard sciences rather than on soft sciences (Kaukonen, 1998). Since the mission of the Framework Programmes is the strengthening of the EU's competitiveness vis à $v i s$ her international competitors in the medium term, the direct influence of basic science research and the soft sciences on this aspect may be limited. Keeping in mind the impact that, for example, joblessness and social disintegration have on the competitiveness of Europe it seems not advisable to downsize this S\&T sectors' contribution to shortly above zero, as was suggested by the European Commission in its proposal for the Fifth Framework Programme. One might even be led to believe that the role of the soft sciences is currently underrated in this respect.

On another note, an important prob- lem of the Framework Programmes always has been the inflexibility of the initiatives. The foundation of the problem is already laid with the development of the respective Programme. After a Programme has been constructed, it is subject to a number of regulations in the form of legal decisions ${ }^{19}$, which make it difficult to react to real world problems as the BSE (mad cows disease)-syndrome or public discussions on bio-engineered soy beans, to name just two of the more prominent examples of the most recent past. These problems are not waiting in the ranks until the five-year cycle of a Framework Programme has come to an end and a new Programme finally can react to such a challenge..$^{20}$

A number of proposals has been already made to cope with this problem. In principle this inflexibility may be tackled along two different venues. First, a steering body including representatives of the member states might adopt qualified majority voting for decisions on the Framework Programmes. ${ }^{21}$ An alternative could be the construction of a new administrative unit dealing exclusively with the S\&T programmes. This institution might be granted a special status inside the Commission, so as to serve as a sort of intermediary institution between the EU organs providing the general guidelines for S\&T Programmes and the S\&T communities. ${ }^{22}$

A similar idea has been advanced in the European Parliament, where a division of the political and operational-administrative levels has been demanded. In this proposal several models are discussed, one of which is the development of "virtual institutes", consisting of Commission services, research consortia and the industrial users of the new knowl- 
edge. For each of the key actions foreseen in Framework Programme Five such a virtual institute would be constructed, which in fact is a flexible network (Colling, 1997: 31).

Some of the problems plaguing the EU S\&T initiatives are caused less by the grand design of the S\&T programmes, but by the European Commission's handling of the Programmes. An important problem is that the transparency of decision-making processes regarding $\mathrm{S} \& \mathrm{~T}$ programmes as well as the evaluation of project proposals still is relatively poor. Although the respective criteria are laid out in the application packages for S\&T projects $^{23}$, it remains unclear how the actual decision on the project proposals' quality is felled. Here a more sensible public relations management might be helpful.

Furthermore, according to a number of interview partners, much frustration on the side of the researchers arises out of the time lag between the filing of the proposal and the actual project start, which is at least a year later. Also the slow payment of the Commission is problematic, namely for small research ventures.

It may well be that some of the concerned general directorates are understaffed as the Davignon Report surmises (Davignon 1997), but the Commission's internal communication procedures certainly are problem-ridden too. For instance, the co-operation between the administrative units of the EU is suboptimal in that knowledge on projects with similar topics often is not dispersed among the administrators, leading sometimes to the reinvention of the wheel. The reorganisation of the Commission, which is already under way, may solve this problem.
Nevertheless, it should be mentioned that the above listed problems, despite their serious consequences for EU S\&T initiatives, are common to national programmes, too. Moreover, besides these negative facets of the EU S\&T programmes, a number of positive aspects of the Framework Programmes should be mentioned. First of all, the Framework Programmes clearly have been accepted by the S\&T community. This fact finds its expression in the large number of filed applications.

Then, without any question the EU Framework Programmes have intensified the co-operation between the national S\&T systems. Despite the relatively far advanced internationalisation of the research sphere, the national borders are, due to language as well as cultural barriers, still a hindrance to the free flow of information. Thereby the EU programmes are targeting a key problem of S\&T in Europe, the continent with the longest national borders in relation to its area.

Furthermore, the EU initiative slowly is decreasing the communication impasse between academic research and industrial research (Reger/Kuhlmann, 1995: 176). Whereas the weak linkage between academia and industry is a problem all over the world, it is especially prevalent in Europe. Finally, there are indications that the most advanced S\&T institutions - perhaps depending also on the analysed discipline - are by and large the most successful in EU projects, so that a network of excellency may be developing in European S\&T (Biegelbauer, 1997).

On a final note, considering the drawbacks and shortcomings, but also the merits of the EU Framework Pro- 
grammes, these initiatives seem worthwhile-especially in light of the complexity of the EU S\&T policy finding processes. For the first time in European history a transnational European S\&T system seems to be in the making, with all the ramifications of such a project for a successful and peaceful social and economic development of the continent.

\section{Notes}

Open interviews, both structured and unstructured, have been carried out at a number of academic and non-academic research institutions in Austria and Germany, as well as the Austrian Ministry for Science and Transport (BMWV).

1 In December 1998, one ECU, the European Currency Unit, is a bit less than 1,2 US Dollar. The ECU is the forerunner of the EURO, which is to be introduced in 1999. Both ECU and EURO have the same value.

2 Data provided by Peter Fisch, DG XII, in a presentation on the Fifth Framework Programme on 24-06-1998.

3 In Table 1 the money spent on the activities of the EU's Joint Research Centre is included. On information regarding the Fourth Framework Programme, see for example European Commission 1994 and $1997 \mathrm{a}$.

4 Presently the EU consists of Austria, Belgium, Denmark, Finland, France, Germany, Greece, Ireland, Italy, Luxembourg, the Netherlands, Portugal, Spain, Sweden and the United Kingdom.

5 Some interviewed evaluators were of the opinion that they have either been subject to pressure of the Commission or their evaluation results were not fully taken into account. Moreover, the fact that project proposals have been up- or downgraded or cut and/or fused after the actual evaluation process have been interpreted as another of the Commission's entrance points at the very end of the evaluation, selection and negotiation process.

6 A number of different committee forms exist in the EU, of which the programme management committees are the most powerful as they decide over budgets. See, for example, Guéguen, 1991; on a more analytic level, Töller, 1998. It is important to notice that the $\operatorname{com}(\mathrm{m})$ itology, which has been a hotly discussed feature of EU administration and policy-making, currently is in a process of reform: see Lake 1998.

7 It was CREST, for instance, which proposed to use PHARE-money to co-fund the transition countries' participation in the Fifth Framework Programme. More recently CREST emphasised that EU research policy should be an integrative part of structural and enlargement policies: see Der Standard, 11-09-1998.

8 As of December 1998, IRDAC and ESTA have been dissolved, but are to be replaced by similar organs.

9 This short abridgement of theory-building is largely based upon O'Neill's reader (O’Neill, 1996). O'Neill quite rightly points out that all the listed theories still do have an impact on nowadays understanding of the European integration process and even are used explicitly or implicitly for analytic purposes.

10 Very influential was Fritz Scharpf's comparison of German and European political processes in Scharpf 1995. Pertaining to the analysis of European S\&T Policies, see, Grande, 1996; a similar understanding forms the basis of Grande, 1995 and Kaukonen, 1998.

11 The concept of cleavages is taken from Seymour Martin Lipset's original work. In this paper the notion signifies deep rifts in the interest structure of the EU institutions' and member states' S\&T governance. See Lipset, 1964.

12 This division is based on Edgar Grande's work; he finds three lines of division in Grande, 1995. 
13 A more comprehensive view on science in small countries is provided in Kaukonen, 1990..

14 As an example might suffice that the ESPRIT initiative was pushed by France, but initially opposed by Germany and the UK; see Süß, 1993: 307.

15 The fact that the four above countries for a long time have opposed any budget raise of the Fifth Framework Programme, while a number of countries were rather indifferent to budget changes, whereas Ireland explicitly favoured such a raise - which, to a lesser degree is true for Portugal, Spain and Greece, too - is a good example of the diversity in the opinions of the fifteen member states.

16 In Grande 1995 S\&T policy-finding processes in Germany and the EU are compared and a number of similarities analysed.

17 In German the term "Realverfassung" (real or actual constitution) has been created to explain this phenomenon, signifying the differences between the content of the constitutions as found in exact textbook interpretations and the much more flexible interpretations of political actors caused by the necessities of daily policyfinding processes.

18 In fact, one of the aspects of the ongoing discussion on the EU S\&T initiatives focuses on the question if the structural funds could be used rather for the purpose of regional cohesion and the Framework Programmes rather for scientific excellency.

19 The Davignon Report finds 25 such regulations for the Fourth Framework Programme alone: see Davignon, 1997.

20 It should be mentioned that the Commission has reacted to the BSE problem outside the instrument of the Framework Programmes, creating a network of research groups, which had not known from each others existence before. It remains to be seen how effective this network is. Moreover the BSE-scandal has led to a certain opening up of the European Com- mission with respect to this specific case. At the moment it is unclear if this will lead to a wider policy-change of the EU.

21 Compare with the Davignon Report's recommendation to use the Inter Governmental Conference for such a function.

22 Compare with the more radical suggestions of Hans-Heinrich Trute, who sharply criticises the underrepresentation of the science community in the EU organs (Trute, 1994, p. 5). The establishment of ESTA has only marginally changed this situation.

23 In the case of the Fourth Framework Programme's social science programme TSER, large progress has been made from the first to the third call, where the respective criteria have been made already quite clear.

\section{References}

Der Standard

1998 "EU-Wissenschaftsrat will Beitrittswerber einbinden" (EU-Science Council Wants to Incorporate Enlargement Candidates). 11-09-1998 P.10 in Der Standard, Austrian newspaper.Vienna. Berka et al. (ed.)

1994 Kooperation und Konkurrenz (Co-operation and Competition). Vienna.

Biegelbauer, P.

1997 "Probing the Austrian Innovation System". Working paper number 13 of the Institute for Advanced Studies' Sociological Series. Vienna.

Burgess, M.

1989 (orig.) The European Community's federal heritage. Federalism and the European Union. Routledge. Reprinted in O'Neill 1996.

Colling, F.

1997 "Überlegungen zu Neuen Ansätzen im Bereich des R\&D Managements" (Some Thoughts on New Approaches in the Area of R\&D Management). Testimony before the Committee on Research, Technological Development and Energy of the European Parliament in September 1997. 
Cresson, E.

1998 “Forschungsbudget nicht kürzen!” (Do Not Cut the Research Budget!) 09-041998 in Der Standard, Austrian newspaper. Vienna.

Davignon, E.

1997 5-Year Assessment of the European Community RTD Framework Programmes. Study prepared by an independent panel chaired by Viscount E. Davignon.

European Commission

1970 "The Industrial Policy of the Community". Report of the European Commission to the European Council.

1992 "Forschungs- und Technologieförderung der EG” (R\&D Financing by the EC). Report. Luxembourg.

1994 "Das 4. Rahmenprogramm" (The $4^{\text {th }}$ Framework Programme). Brochure. Luxemburg.

1995 Greenbook On Innovation. Luxembourg.

1997a "Yearly Report on R\&D Activities for 1996". Kom (97) 373. July 1997.

1997b Retrieval at 14-12-1997, "The Fifth Framework Programme: Summary of Select Country Positions", http:/ /www. cordis.lu/fifth/

1998a Retrieval at 10-03-1998. Created at 1601-1998. http://www.cordis.lu/info/ frames/if006_en.htm

1998b Retrieval at 10-03-1998. Created at 17-02-1998. http://www.cordis.lu/ fifth/src.cp.htm.

1998c Retrieval at 19-05-1998. Created at 04-1998. "Conclusions and Recommendations of IRDAC". http://www. cordis.lu/fifth/

1998d Retrieval at 09-07-1998. Created at 19-06-1998. "Specific programme proposals adopted by the Commission". http://www.cordis.lu/fifth/

1998e Retrieval at 09-07-1998. Created at 22-06-1998. "MEPs maintain demands for ECU 16,300 million for Fifth Framework Programme". http://www. cordis.lu/fifth/

European Council and Commission

1992 Vertrag über die Europäische Union (Treaty Concerning the European Union).
Guéguen, D.

1991 A Practical Guide to the Labyrinth of the European Community and its Institutions. Agra Europe.

Grande, E.

1995 "Forschungspolitik in der Politikverflechtungs-Falle?" Politische Vierteljahresschrift 36, 3: 460-483.

1996 "Das Paradox der Schwäche. Forschungspolitik und die Einflußlogik europäischer Politikverflechtung." Pp.373 in Jachtenfuchs, M. \& KohlerKoch, B. Europäische Integration (European Integration). Leske + Budrich.

Haas, E.B.

1968 (orig.) The Uniting of Europe: Political, Social and Economic Forces: 19501957. Stanford University Press. Reprinted in O'Neill 1996.

Hoffmann, S.

1964 (orig.) "The European process at Atlantic cross purposes". Journal of Common Market Studies 3. Reprinted in O’Neill 1996.

1966 (orig.) "Obstinate or obsolete? The Fate of the Nation-State and the Case of Western Europe". Daedalus 95. Reprinted in O'Neill 1996.

Kaukonen, E.

1990 Theory, Dynamics and Policy of Science - Science Studies from a Small Country Perspective. University of Tampere.

1998 "European S\&T From a Small Country Perspective". Paper presented 18-091998 at the Workshop "European S\&T: Still in the Ivory Tower?" during the $3^{\text {rd }}$ Joint ECPR-SGIR/ISA Conference in Vienna.

Lake, G.

1990 "2(b) or not 2(b): that is the question: commitology, scientific advice, and open decision-making in the EU". Paper presented 01-10-1990 at the EASST '98 Conference. Lisbon.

Lipset, S. M.

1964 "Political Cleavages in "Developed" and "Emerging" Polities" in Allardt, E \& Littunen, Y., Cleavages, Ideologies and Party Systems. The Westermarck Society. 
O’Neill, M.

1996 The Politics of European Integration. Routledge.

Peschke, A.

1998 “Transnationale Interessenvermittlung und Kooperation in der Europäischen Forschungs- und Technologiepolitik" (Transnational Interest Aggregation and Co-operation in the European Research and Techno-logy Policy). Paper presented 05-06-1998 at the "Europa zwischen Integration und Ausschluß" (Europe between Integration and Exclusion) Conference. Vienna.

Reger, G. \& Kuhlmann, S.

1995 Europäische Technologiepolitik in Deutschland (European Technology Scharpf, F. Policy in Germany). Physica Verlag.

1995 "Die Politikverflechtungs-Falle: Europäische Integration und deutscher Föderalismus im Vergleich" (The Joint Policy-Trap: European Integration and German Federalism in Comparative Perspective"). Politische Vierteljahresschrift 26: pp.324-356.

Servan-Schreiber, J-.J.

1968 Le Défi American (The US-American Challenge). Paris: Denoel.

Sharp, M.

1998 "Competitiveness and Cohesion - Are the two Compatible?" Research Policy 27: pp.569.

Sturm, R. (ed)

1996 Europäische Forschungs- und Technologiepolitik und die Anforderungen des Subsidiaritätsprinzips (European Research and Technology Policy and the Challenge of the Subsidiarity Süß, W. Principle). Nomos Verlagsgesellschaft.

1993 "Das Technologieargument im Integrationsprozeß" (The Technology Argument in the Integration Process).
Pp.295 in: Süß, W. \& Becher, G. (ed.), Politik und Technologieentwicklung in Europa (Politics and Technological Development in Europe). Duncker \& Humblot.

Süß, W. \& Becher, G. (ed.)

1993 Politik und Technologieentwicklung in Europa (Politics and Technological Development in Europe). Duncker \& Humblot.

Töller, A. E.,

1998 "Die Komitologie-Funktionsweise und Reformperspektive" (The Comi-tology - Functioning and Perspectives of Reform). Paper presented 05-06-1998 at the "Europa zwischen Integration und Ausschluß" (Europe between Integration and Exclusion) Conference. Vienna.

Trute, H.-H.

1994 "Comparative Analysis of European Research policy Structures". In: European Research Structures, Max Planck Gesellschaft.

Webb, C.

1983 (orig.) "Theoretical perspectives and problems", in Wallace, $\mathrm{H} \&$ Wallace, W. et al, Policy-Making in the European Community, John Wiley and Sons Ltd. Reprinted in O'Neill 1996.

Widder, C.

1996 "Der Forschungspolitische Entscheidungsprozess in der Europäischen Union", (The Decision-Making Process in EU Research Policy). Master Thesis. University of Vienna.

Wistrich, E.

1988 (revised ed.) A federal democracy. After 1992: The United States of Europe. Routledge. Reprinted in O’Neill 1996.

Peter S. Biegelbauer

Institute for Advanced Studies

Austria 